\title{
INDUCCIÓN EFICIENTE DE BROTES ADVENTICIOS EN COTILEDONES DE PINUS MAXIMARTINEZII RZEDOWSKI
}

\author{
Alejandrina Robledo Paz ${ }^{1}$, Víctor Manuel Villalobos Arámbula² y \\ Amalio Santacruz Varela ${ }^{1}$
}

${ }^{1}$ Colegio de Postgraduados, Posgrado en Recursos Genéticos y Productividad, Campus Montecillo. km 36.5 carretera México-Texcoco, 56230 Texcoco, Estado de

México, México.arobledo@colpos.mx, asvarela@colpos.mx.

${ }^{2}$ Secretaría de Agricultura, Ganadería, Desarrollo Rural, Pesca y Alimentación.

Avenida Municipio Libre núm. 377. Colonia Santa Cruz Atoyac, 03310 México, D.F. vvilla@sagarpa.gob.mx.

\section{RESUMEN}

Pinus maximartinezii Rzedowski es una especie de piñonero originaria de México, considerada en peligro de extinción debido a la alteración de sus poblaciones y de su hábitat, así como a su distribución geográfica restringida. A pesar de que tecnologías como el cultivo de tejidos podrían ser una alternativa para su conservación y propagación, la literatura existente al respecto es escasa. En este trabajo se presenta un protocolo que permite la diferenciación eficiente de brotes adventicios de este taxon. Se probaron embriones y cotiledones en cuanto a su capacidad para formar yemas adventicias. Los segundos mostraron la mejor respuesta y fueron entonces cultivados en el medio de Schenk y Hildebrandt ( $\mathrm{SH}$ ) modificado, suplementado con cuatro concentraciones (2.2 a $16.8 \mathrm{mg} \mathrm{L}^{-1}$ ) de $\mathrm{N}^{6}$-benciladenina (BA). El porcentaje de explantes que produjeron brotes y el número de brotes formados en éstos fue estadísticamente diferente entre los niveles de BA probados; con $16.8 \mathrm{mg} \mathrm{L}^{-1}$ se indujo el mayor porcentaje de órganos que formaron brotes (53.5) y el número más alto de brotes generados por explante (29.1) a las 14 semanas de cultivo; de los vástagos individualizados, $3 \%$ formó raíces. La metodología desarrollada permite la diferenciación de yemas adventicias de $P$. maximartinezii a partir del cultivo de cotiledones, con una tasa de multiplicación significativamente superior a la obtenida por otros autores.

Palabras clave: cultivo de tejidos, micropropagación, organogénesis, Pinus maximartinezii. 


\section{ABSTRACT}

Pinus maximartinezii Rzedowski is a nut pine native to Mexico that currently is considered as an endangered species because of disturbance of populations and natural habitat, as well as its limited geographic distribution. Even though such technologies as tissue culture could represent an alternative for its conservation and propagation, the existing literature for this pine is scarce. In this paper a protocol that allows an efficient differentiation of adventitious shoots for this species is presented. Different types of explants (embryos and cotyledons) were evaluated regarding their capacity to differentiate adventitious shoots. Explants from cotyledons showed the best response, so they were cultivated in a modified Schenk and Hildebrandt (SH) medium supplemented with four different concentrations (2.2$16.8 \mathrm{mg} \mathrm{L}^{-1}$ ) of $\mathrm{N}^{6}$-benzyladenine (BA). Percentages of explants forming shoots and number of shoots developed per explant were statistically different among the tested concentrations. The $16.8 \mathrm{mg} \mathrm{L}^{-1}$ of BA concentration induced the largest percentage of explants forming shoots (53.5) and the highest number of shoots developed per explant (29.1) after 14 weeks of culture. Three percent of the individual shoots produced roots. The developed methodology allows differentiation of adventitious shoots of Pinus maximartinezii from cotyledon explants, with a multiplication rate significantly higher than the one obtained by other authors.

Key words: micropropagation, organogenesis, Pinus maximartinezii, tissue culture.

\section{INTRODUCCIÓN}

Pinus maximartinezii es una de las 12 especies conocidas de pinos piñoneros americanos, es originaria de México y su distribución geográfica está sumamente restringida, ya que se le encuentra sólo en un diminuto sector del estado de Zacatecas. Este reducto ecológico cuenta con una superficie aproximada de 400 ha y la población se estima entre 2000 y 2500 árboles maduros (Donahue y Mar-López, 1995; López-Mata, 2001).

La reproducción de la especie es difícil debido a que prácticamente todas sus semillas son utilizadas para consumo humano o para el comercio local; además de verse afectada por el sobrepastoreo, los incendios forestales inducidos y los cambios en el uso del suelo. El tamaño limitado de la población, su baja tasa de propagación y la dificultad para proteger el territorio en que este piñonero se distribuye, lo sitúan dentro del conjunto de las especies en peligro de extinción, 
de acuerdo con la Norma Oficial Mexicana, NOM-059-ECOL-2001 (Anónimo, 2002).

Ante tal panorama resulta necesario buscar una tecnología que permita obtener individuos en grandes cantidades y en menor tiempo que el requerido por los métodos convencionales. El cultivo de tejidos puede ser una alternativa que, aun cuando tenga su principio en la semilla misma, permita hacer de ésta un sistema más eficiente de propagación.

La reproducción in vitro de pináceas como Pinus sylvestris (Lelu et al., 1999), Pinus pinea (Gónzalez et al., 1998), Pinus banksiana (Pelletier y Laliberté, 2000), Picea glauca (Ashihara et al., 2001) y Pinus virginiana (Tang et al., 2004) se ha llevado a cabo utilizando embriones u órganos de plántulas, como los cotiledones. El uso de estos últimos representa ventajas sobre el cultivo de embriones, entre las cuales está el incremento de la superficie de tejido en contacto con el medio nutritivo y la obtención de mayor número de explantes por semilla empleada, considerando que en la mayoría de los pinos ésta tiene al menos ocho cotiledones (Saborio et al., 1997).

Aunque existen varios trabajos que describen protocolos de propagación in vitro de distintas especies de Pinus ( $P$. halepensis, $P$. canariensis, $P$. ayacahuite, $P$. pinea, P. heldreichi, P. tadea) (Lambardi et al., 1991; Martínez-Pulido et al., 1994; Saborio et al., 1997; González et al., 1998; Stojicic et al., 1999; Tang y Guo, 2001; Sul y Korban, 2004), sólo se conoce uno referente al cultivo de tejidos en Pinus maximartinezii (Villalobos-Amador et al., 2002). En éste, los autores utilizaron embriones maduros como explante para inducir brotes adventicios; sin embargo, la tasa de multiplicación obtenida fue baja (14.6 brotes por embrión). Por lo anterior, la presente investigación tuvo como objetivo desarrollar un protocolo para diferenciar in vitro brotes adventicios de $P$. maximartinezii, que basado en el uso de los cotiledones como explantes, permitiera mejorar tanto la respuesta morfogenética como el número de vástagos obtenidos mediante el cultivo de embriones.

\section{MATERIAL Y MÉTODOS}

Material biológico

Se utilizaron semillas maduras de Pinus maximartinezii, con un año de haber sido cosechadas y almacenadas a temperatura ambiente, provenientes de polinización abierta, colectadas en el estado de Zacatecas, México. 
Medios de cultivo

La composición de los medios de cultivo usados en la presente investigación se describe en el Cuadro 1. Todos ellos fueron suplementados con $0.7 \%(\mathrm{p} / \mathrm{v})$ de agar-agar. El pH se ajustó a $5.7 \pm 0.1$ y la esterilización se realizó en autoclave a 1.05 $\mathrm{kg} \mathrm{cm}^{-2}$ y $121{ }^{\circ} \mathrm{C}$, durante $15 \mathrm{~min}$.

Desinfección y germinación de las semillas

Con el objeto de obtener plántulas en condiciones asépticas, que permitieran la mejor respuesta de los explantes in vitro, se probaron dos métodos de desinfección-germinación:

a) Desinfección con cloro y germinación en medio de cultivo: se eliminó la testa de 50 semillas en forma mecánica, para posteriormente sumergirlas en agua corriente por 24 horas; después, se desinfectaron con una solución de blanqueador doméstico $(1.8 \% \mathrm{v} / \mathrm{v}$ de cloro activo) durante $20 \mathrm{~min}$, y se les aplicaron tres enjuagues con agua destilada esterilizada. Las semillas se mantuvieron a $4{ }^{\circ} \mathrm{C}$ durante $48 \mathrm{~h}$ (estratificación), dándoles luego una segunda desinfección con cloro a 1.8\% durante 20 min, seguida de tres últimos enjuagues con agua destilada esterilizada. En condiciones asépticas los embriones se disecaron y se colocaron horizontalmente en cajas de Petri con el medio 4 (SH con $5.6 \mathrm{mg} \mathrm{L}^{-1} \mathrm{de} \mathrm{BA}$ ), en el que permanecieron durante siete días.

b) Desinfección y germinación en peróxido de hidrógeno: cincuenta semillas se escarificaron, con ayuda de una lija, por la parte micropilar y se colocaron en un matraz Erlenmeyer que contenía una solución de peróxido de hidrógeno a 3\% (v/v), el cual se cubrió con papel aluminio. La solución se renovó cada dos días hasta la emergencia de la radícula (siete días).

Una vez que las semillas provenientes de ambos tipos de tratamiento germinaron, se les disecaron los cotiledones y se colocaron en cajas de Petri con el medio 4.

Selección de explantes

Se probaron embriones completos germinados en medio de cultivo y cotiledones provenientes de éstos, así como de semillas que germinaron en peróxido de hidrógeno a $3 \%(\mathrm{v} / \mathrm{v})$. Los explantes fueron disecados y colocados en cajas de Petri con medio 4. 
Cuadro 1. Composición de los medios utilizados para la formación de brotes adventicios de P. maximartinezii a partir de cotiledones.

\begin{tabular}{cccc}
\hline Medio & Sales y vitaminas & Sacarosa $(\%)$ & Reguladores de crecimiento $\left(\mathrm{mg} \mathrm{L}^{-1}\right)$ \\
\hline 1 & $50 \%$ SH & 2.0 & \\
2 & SH & 3.0 & \\
3 & SH & 3.0 & BA, 2.2 \\
4 & SH & 3.0 & BA, 5.6 \\
5 & SH & 3.0 & BA, 11.2 \\
6 & SH & 3.0 & BA, 16.8 \\
7 & GD & 2.0 & ANA, 0.5 \\
& & & AIB, 0.05 \\
8 & GD & 2.0 & ANA, 0.5 \\
& & & AIB, 1.0 \\
9 & GD & 2.0 & ANA, 1.0 \\
10 & GD & 2.0 & AIB, 2.0 \\
11 & GD & & AIB, 3.0 \\
12 & GD & & \\
\hline
\end{tabular}

SH, Schenk y Hildebrandt (1972), modificado por Reilly y Washer (1977); GD, Gresshoff y Doy (1972), modificado por Reilly y Washer (1977); BA, N6-benciladenina; ANA, ácido $\alpha$-naftalenacético; AIB, ácido indolbutírico.

Efecto de la benciladenina en la inducción de los brotes adventicios

Los cotiledones obtenidos de las semillas que germinaron en peróxido de hidrógeno se colocaron en forma horizontal en el medio de cultivo, de los cuales 200 se pusieron en cajas de Petri con los medios 3, 4, 5 y 6 (SH adicionado con 2.2, 5.6, 11.2 y $16.8 \mathrm{mg} \mathrm{L}^{-1}$ de $\mathrm{BA}$, respectivamente). Se contó el número de los que formaron brotes a las nueve semanas y la cantidad de éstos que se diferenciaron en cada cotiledón después de 14 semanas de iniciado el experimento.

Desarrollo de los brotes

Una vez que los brotes adventicios se formaron en la superficie de los cotiledones, estos últimos se transfirieron a cajas de Petri con medio 2 ( $\mathrm{SH}$ sin reguladores 
del crecimiento). Cuatro semanas después, los explantes fueron divididos en 3 a 5 partes y se cultivaron en frascos de $250 \mathrm{ml}$ de capacidad, con $30 \mathrm{ml}$ de este mismo medio. Los cotiledones con yemas adventicias se trasladaron al mismo medio fresco cada cuatro semanas. Cuando los vástagos alcanzaron una longitud aproximada de $0.6 \mathrm{~cm}$, se separaron del explante inicial y se colocaron individualmente en tubos de ensaye de cristal de $80 \times 20 \mathrm{~mm}$, con $15 \mathrm{ml}$ de medio 1 ( $\mathrm{SH}$ a 50\%).

\section{Enraizamiento}

Cuarenta y cinco brotes de 2.0 a $2.5 \mathrm{~cm}$ de longitud se cultivaron individualmente en tubos de ensaye $(80 \times 20 \mathrm{~mm})$ con $15 \mathrm{ml}$ del medio Gresshoff y Doy (GD) con 0.0 a $2.0 \mathrm{mg} \mathrm{L}^{-1}$ de ácido $\alpha$-naftalenacético (ANA) y 0.05 a $5.0 \mathrm{mg} \mathrm{L}^{-1}$ de ácido indolbutírico (AIB) (medios 7, 8, 9, 10 y 11) (Cuadro 1). Cada 10 días, durante 30 jornadas, 15 de éstos se transfirieron al medio GD sin reguladores (medio 12), para promover el crecimiento de raíces.

Condiciones de incubación de los cultivos

Todos los cultivos fueron incubados en un cuarto de ambiente controlado a $27 \pm 2{ }^{\circ} \mathrm{C}$ y fotoperíodo de 16 horas (lámparas de luz blanca fría fluorescente, con intensidad lumínica de $\left.25 \mu \mathrm{mol} \mathrm{m} \mathrm{m}^{-2} \mathrm{~s}^{-1}\right)$.

Diseño experimental y análisis estadístico

En la prueba de germinación se empleó un diseño experimental completamente al azar, con dos tratamientos (medio de cultivo y peróxido de hidrógeno) y dos repeticiones, utilizando para cada una de ellas un conjunto de 50 semillas. Las variables de respuesta consideradas fueron: el porcentaje de semillas que germinaron y el número de éstas que mostraron contaminación.

Para evaluar el comportamiento de los dos tipos de explante (embriones y cotiledones) se usó una disposición similar, con dos repeticiones de 25 entes cada una. El efecto de la BA en la inducción de brotes adventicios se estudió utilizando un procedimiento experimental análogo, con cuatro concentraciones de este regulador de crecimiento $\left(2.2,5.6,11.2\right.$ y $\left.16.8 \mathrm{mg} \mathrm{L}^{-1}\right)$, aplicadas a través de los medios $3,4,5$ y 6 , respectivamente (Cuadro 1). Se registró el porcentaje de individuos que emitieron brotes a las nueve semanas de haber iniciado el cultivo; para esta variable se establecieron diez repeticiones y la unidad de estudio se integró con un 
grupo de 20 explantes. Adicionalmente, se registró el número de yemas adventicias producidas por explante a las 14 semanas de establecer el cultivo; en este caso se consideraron 13 repeticiones, siendo la unidad de estudio cada cotiledón proveniente de una muestra de aquellos que emitieron brotes. Todos los valores que se registraron en porcentaje se sometieron a una transformación logarítmica de base 10 , previo al análisis de varianza, y se utilizó como prueba de comparación de medias la diferencia mínima significativa (DMS, 0.05), expresando los promedios en las unidades originales. Los datos se analizaron mediante el Sistema de Análisis Estadístico (Anónimo, 1999).

\section{RESULTADOS Y DISCUSIÓN}

Desinfección y germinación de semillas

Un serio problema en este estudio fue el alto índice (80\%) de afectación microbiana de las semillas, el cual se superó cuando se les retiró la testa y se sumergieron en dos ocasiones en la solución de hipoclorito de sodio a $1.8 \%(\mathrm{v} / \mathrm{v})$, o bien cuando se les dispuso a germinar en presencia de peróxido de hidrógeno a 3\% (v/v), obteniendo en ambos casos $100 \%$ de ellas libres de infección.

Noventa y seis por ciento de los embriones obtenidos de las semillas desinfectadas con hipoclorito de sodio y colocados en medio de cultivo al momento de ser disecados, germinaron después de siete días, adquiriendo una coloración verde que no fue homogénea para toda la estructura, sino sólo para la parte que no se encontraba en contacto con el medio de cultivo (50\%); el resto del embrión permaneció blanco.

El tratamiento con peróxido de hidrógeno es un método utilizado para acelerar la germinación (Takacs, 1964); adicionalmente, Barnett (1977) encontró que éste permitía reducir o eliminar la microflora de las semillas de especies forestales. Tales observaciones se corroboraron con el método empleado en este estudio en el tratamiento de las semillas de $P$. maximartinezii, al resultar sanas durante la germinación y cuando sus cotiledones fueron disecados y establecidos en un medio de cultivo en condiciones asépticas.

Por otra parte, el tratamiento de las semillas con peróxido de hidrógeno permitió la germinación (emergencia de la radícula) de $70 \%$ de éstas después del séptimo día, momento en el cual los embriones presentaron diferentes tonalidades. La discrepancia en color se asoció con la del largo de los cotiledones y la del tamaño de la radícula, el blanco correspondió a cotiledones y radícula de menor talla 6 y 
$3 \mathrm{~mm}$, respectivamente) y el verde intenso a los de mayor longitud (10 y $6 \mathrm{~mm}$, en forma análoga).

A pesar de las diferencias observadas en términos numéricos en los porcentajes de germinación registrados para los dos métodos probados, éstas no fueron estadísticamente significativas, lo que implica que fueron originadas preponderantemente por variación aleatoria más que por aquella atribuible a los tratamientos; sin embargo, todos los cotiledones de las semillas que lograron germinar en peróxido adquirieron color verde; por ello se consideró a este último como el mejor método de germinación y fue el que se empleó en los siguientes experimentos.

Selección de los explantes

Los embriones que germinaron en medio de cultivo (medio 4) crecieron y adquirieron coloración verde a los siete días, pero conforme transcurrió el tiempo sus hipocótilos y cotiledones se hincharon hasta convertirse en una masa amorfa de tejido, de la cual no se diferenciaron brotes adventicios. Después de ocho semanas se tornaron de color café y murieron.

El efecto negativo causado por la presencia de BA $\left(5.6 \mathrm{mg} \mathrm{L}^{-1}\right)$ (medio 4) en los embriones de P. maximartinezii expuestos a este regulador, inmediatamente después de su disección, concuerda con lo observado por Saborio et al. (1997), quienes cultivaron los de $P$. ayacahuite al momento de ser extraídos del megagametofito, en un medio que contenía BA ( $\left.2.2 \mathrm{mg} \mathrm{L}^{-1}\right)$. Los mencionados autores obtuvieron menos brotes adventicios en esta condición que en un medio carente de BA durante los primeros días de cultivo. No obstante, tal comportamiento contrasta con lo registrado por Villalobos-Amador et al. (2002), quienes cultivaron embriones de P. maximartinezii recién disecados en un medio con BA $\left(3.9 \mathrm{mg} \mathrm{L}^{-1}\right)$ y lograron la generación de yemas adventicias.

La falta de respuesta morfogenética de los embriones de $P$. maximartinezii a los tratamientos probados en la presente investigación podría deberse no sólo al efecto de la BA, sino al contenido de sales del medio SH, diferente al del MS (Murashige y Skoog, 1962), empleado por Villalobos-Amador et al. (2002), así como al manejo (estratificación) de las semillas antes de disecar y hacer crecer sus embriones en estas condiciones.

Los explantes de cotiledón cultivados en el medio de inducción (medio 4), tanto los que provenían de la germinación en peróxido como en medio de cultivo, se alargaron y engrosaron después de nueve días; sin embargo, algunos de los obtenidos por el segundo método se observaron suculentos y rugosos, volviéndose a la 
vez translúcidos, y conforme transcurrió el tiempo se tornaron obscuros y murieron. Los explantes que estuvieron en contacto con el medio durante la germinación no mostraron respuesta morfogenética, y sólo algunos (2\%) de los que se mantuvieron alejados de él desarrollaron brotes. En contraste, $32 \%$ de los cotiledones obtenidos de semillas que se desarrollaron en peróxido logró diferenciar yemas adventicias.

El análisis estadístico de los resultados indicó que de los distintos tipos de explante probados, los cotiledones de semillas que habían germinado en peróxido mostraron la mejor respuesta a las condiciones de cultivo ensayadas, por lo que fueron usados para estudiar el efecto de la BA en la morfogénesis.

Algunos aspectos que confieren a los cotiledones características favorables como explante (Aitken et al., 1981; Saborio et al., 1997) son: a) la capacidad para establecer mejor contacto con el medio de cultivo debido a su morfología y a que todos los cotiledones de un embrión quedan expuestos al medio nutritivo y no sólo $50 \%$ de ellos, como ocurre cuando se usan embriones completos; b) la inducción de brotes adventicios no experimenta fase de callo; c) la distribución de las yemas adventicias y su crecimiento es más homogéneo; d) la tasa de multiplicación se magnifica, particularmente en especies que, como $P$. maximartinezii, cuentan con un alto número de cotiledones por semilla.

Efecto de la benciladenina en la diferenciación de brotes adventicios

Los cotiledones cultivados en las distintas concentraciones de BA probadas (medios 3, 4, 5 y 6) formaron brotes adventicios. El análisis de varianza mostró diferencias altamente significativas entre los niveles de concentración usados (Cuadro 2). Así, $16.8 \mathrm{mg} \mathrm{L}^{-1}$ indujeron el mayor porcentaje de cotiledones que produjeron yemas adventicias (53.5) y el número más alto de éstas por explante (29.1), mientras que los cotiledones cultivados en $2.2 \mathrm{mg} \mathrm{L}^{-1}$ tuvieron la menor respuesta para ambas variables analizadas. Los resultados anteriores indican que la BA aplicada en forma exógena puede inducir la organogénesis en cotiledones de $P$. maximartinezii al igual que lo encontrado en otras coníferas como $P$. pinea, $P$. pinaster y $P$. ayacahuite (Capuana y Giannini, 1995; Calixto y Pais, 1997; Saborio et al., 1997; Sul y Korban, 2004).

Los cotiledones cultivados en la concentración más baja de BA (medio 3) formaron brotes, especialmente en la zona de corte y las puntas, mientras que el incremento de $\mathrm{BA}$ en el medio promovió que un mayor número de células entrara al proceso organogenético y con ello las yemas adventicias se distribuyeron de manera más homogénea en la superficie de los explantes; en el caso de aquellos cultivados 
Cuadro 2. Porcentajes de explantes de Pinus martinezii que diferenciaron brotes (a las 9 semanas) y el número de éstos por explante (a las 14 semanas) en cuatro medios de cultivo.

\begin{tabular}{ccc}
\hline Medio de cultivo & Explantes con brotes $(\%)$ & Núm. de brotes por explante \\
\hline 3 & $34.5 \mathrm{c}$ & $7.2 \mathrm{c}$ \\
4 & $44.5 \mathrm{~b}$ & $14.3 \mathrm{~b}$ \\
5 & $44.5 \mathrm{~b}$ & $17.0 \mathrm{~b}$ \\
6 & $53.5 \mathrm{a}$ & $29.1 \mathrm{a}$ \\
DMS $(0.05)$ & 7.28 & 5.40 \\
\hline
\end{tabular}

Promedios con diferente letra en las columnas son estadísticamente diferentes (DMS, 0.05).

en la concentración de BA más alta (medio 6) prácticamente todo el cotiledón logró desarrollar vástagos. Un comportamiento similar lo observaron Biondi y Thorpe (1982) en cotiledones de $P$. radiata y Martínez-Pulido et al. (1992) en $P$. canariensis al usar diferentes concentraciones de BA.

Cabe señalar que aun la concentración más baja de BA $\left(2.2 \mathrm{mg} \mathrm{\textrm {L } ^ { - 1 }}\right)$ (medio 3) usada permitió triplicar ( 7 cotiledones de una semilla formaron 7.2 brotes cada uno) (Cuadro 2) la respuesta obtenida por Villalobos-Amador et al. (2002) (14.6 brotes por semilla) al utilizar embriones como explante. De hecho, considerando que la semilla de $P$. maximartinezii posee 20.5 cotiledones en promedio y que $53 \%$ de éstos formaron brotes cuando se cultivaron en la concentración más alta de BA empleada (medio 6), sería posible obtener hasta 314 yemas adventicias por semilla en 14 semanas. Dicha tasa de inducción de brotes adventicios no se había dado a conocer antes para ninguna especie de Pinus, ya que para $P$. echinata, $P$. viginia, $P$. bankisiana, $P$. heldreichi y $P$. tadea se habían obtenido 39, 91, 14, 16 y 32 brotes por semilla, respectivamente (Jang y Tainter, 1991; Harry y Thorpe, 1994; Stojicic et al., 1999; Tang y Guo, 2001).

Diferenciación y desarrollo de los brotes

Durante los primeros siete días en presencia de BA, los cotiledones adquirieron un color verde más intenso e incrementaron en un tercio su longitud inicial (10 $\mathrm{mm}$ ) (Fig. 1A). A los 14 días en cultivo alcanzaron el doble de su longitud y volumen, y a los 21 fue posible observar tejido meristemático en su superficie (protuberancias) (Fig. 1B), a partir del cual se diferenciaron primordios de brote dos semanas más tar- 
Robledo Paz et al.: Inducción eficiente de brotes adventicios en cotiledones de Pinus maximartinezii
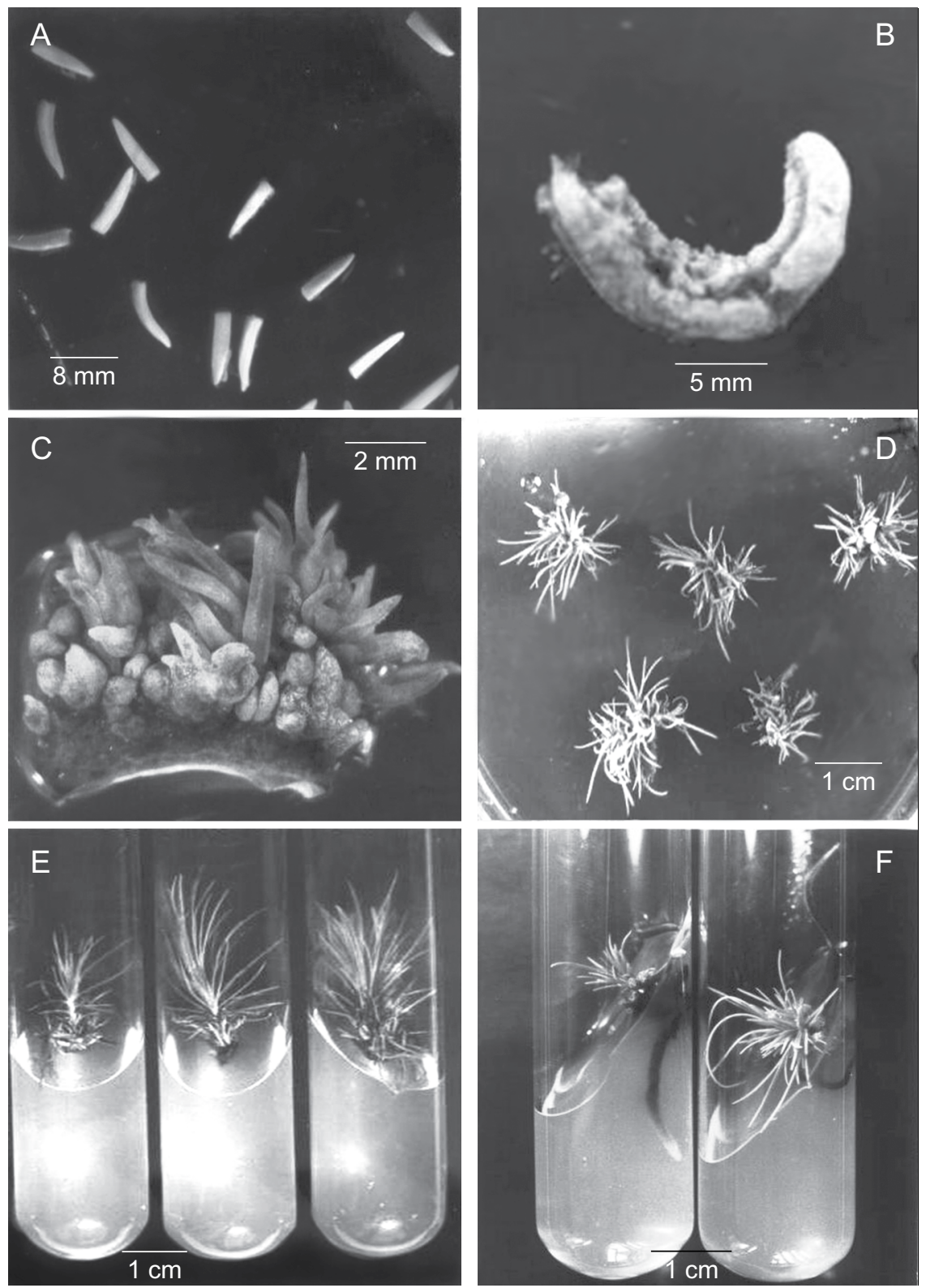

Fig. 1. Diferenciación de brotes adventicios en cotiledones de P. maximartinezii en diferentes tiempos del cultivo. A. cotiledones después de siete días en medio con BA; B. formación de tejido meristemático en la superficie de los cotiledones a los 21 días; C. brotes adventicios después de 34 días; D y E. brotes a las 14 y 25 semanas; F. plantas después de 28 semanas. 
de (Fig. 1C), mismas que dieron lugar a vástagos cuando se les cultivó en un medio sin BA (medio 2) (Fig. 1D).

Cabe señalar que la transferencia de los explantes al medio sin BA no fue suficiente para el desarrollo de las yemas, ya que sólo algunas lograron crecer en estas condiciones, siendo necesario dividir el cotiledón para promover el crecimiento de un mayor número; así, mientras menor fue la cantidad de brotes unidos al explante, éstos alcanzaron mayor longitud en menos tiempo.

Por otro lado, el tamaño de los brotes al momento de aislarlos del explante y hacerlos crecer individualmente fue importante, ya que los muy pequeños no continuaron su crecimiento, en cambio los que medían $6 \mathrm{~mm}$ o más, tuvieron mayor índice de supervivencia (Fig. 1D y 1E).

En P. maximartinezii no se observó una diferencia clara en el crecimiento de los brotes inducidos en los distintos niveles de BA y sólo al emplear la dosis más baja (2.2 $\left.\mathrm{mg} \mathrm{L}^{-1}\right)$, éstos crecieron un poco más rápido. Lo anterior pudo deberse a que los cotiledones cultivados en esta concentración generaron menor número de ellos y, por lo tanto, hubo menos competencia por espacio y nutrientes en relación a los diferenciados en explantes con mayor cantidad de los mismos. Dicha respuesta coincide con lo observado por Von Arnold y Eriksson (1981) en yemas adventicias de $P$. contorta inducidas con concentraciones altas de BA $\left(22 \mathrm{mg} \mathrm{L}^{-1}\right)$, las cuales se desarrollaban más lentamente que las formadas en aquellas más bajas $\left(0.2 \mathrm{mg} \mathrm{L}^{-1}\right)$.

Por otro lado, los brotes diferenciados en la sección del cotiledón que estuvo en contacto con el medio de cultivo por lo general crecieron hacia el interior del mismo, siendo común que adquirieran un color verde y se volvieran translúcidos y suculentos (hiperhidratación), características que no mostraban los que se formaron en la parte del explante opuesta al agar nutritivo. Brotes similares se generaron en cotiledones de P. ayacahuite expuestos a BA (Saborio et al., 1997). La apariencia hiperhidratada se ha asociado con la composición química del agente gelificante, el daño causado a los brotes y la posición de éstos respecto al medio en las fases iniciales de la diferenciación (Nairn et al., 1995; Saborio et al., 1997).

\section{Enraizamiento}

Aunque los brotes adventicios de algunas especies forestales como $P$. banksiana y $P$. pinea desarrollan su sistema radical sin aplicación exógena de auxinas (Harry y Thorpe, 1994; González et al., 1998), o responden positivamente a los tratamientos con estos reguladores de crecimiento, como es el caso de P. nigra (López et al., 1996), P. pinaster (Calixto y Pais, 1997) y P. heldreichii (Stojicic et al., 1999); otros, como 
los de P. pinceana (Villalobos-Amador et al., 2002), forman raíces en baja proporción (7\%) aun después de tratarlos con niveles altos de auxinas $\left(39 \mathrm{mg} \mathrm{L}^{-1}\right)$.

En P. maximartinezii, a pesar de haber probado varios tratamientos para estimular la formación de raíces, únicamente el medio que contenía $3 \mathrm{mg} \mathrm{L}^{-1}$ de AIB (medio 10) logró inducir esta respuesta en 3\% de los brotes (Fig. 1F). Por otra parte, el empleo de ANA solo o en combinación con AIB promovió la formación de callo en la zona del vástago que se encontraba en contacto con el medio de cultivo. Esta masa de células indiferenciadas se hizo más evidente cuando los brotes se expusieron a estas auxinas por tiempos prolongados, como lo indican Villalobos-Amador et al. (2002), y en ocasiones su crecimiento fue tal que se extendió a las hojas basales.

Los resultados obtenidos confirman lo observado por Villalobos-Amador et al. (2002), quienes informan que los brotes adventicios de P. maximartinezii (diferenciados a partir de embriones), mostraron baja eficiencia de enraizamiento. Dichos autores probaron cinco distintas concentraciones y combinaciones de fitorreguladores (BA, AIB y ANA) y sólo lograron inducir raíces en $13 \%$ de los brotes después de mantenerlos durante $4 \mathrm{~h}$ en presencia de $39 \mathrm{mg} \mathrm{L}^{-1}$ de AIB y $9.6 \mathrm{mg} \mathrm{L}^{-1}$ de BA.

Se ha propuesto que la capacidad de enraizamiento está relacionada con el tipo de citocinina usada para la inducción de yemas adventicias. Al respecto, Webb y Street (1977) observaron que los brotes de Pinus contorta y Picea sitchensis formaban más raíces cuando empleaban para su diferenciación 2-iP (2-isopenteniladenina) o cinetina (6-furfurilaminopurina), que cuando se utilizaba BA. También encontraron que las citocininas con capacidad alta para promover la formación de yemas, inhibían la generación de raíces.

Los resultados del presente trabajo permiten vislumbrar al cultivo de tejidos como una herramienta valiosa en la propagación de $P$. maximartinezii, ya que esta tecnología hace de la semilla una forma de propagación más eficiente, aspecto relevante si se considera que la sobrecosecha y el comercio de sus semillas son algunos factores que amenazan la supervivencia de esta especie.

El protocolo aquí usado muestra que un manejo distinto al empleado por otros autores (Villalobos-Amador et al., 2002), tanto de las condiciones de germinación de las semillas (en peróxido), como de los niveles de los reguladores de crecimiento utilizados para la inducción (BA), así como del uso de cotiledones como explante, puede generar una forma alternativa de propagación in vitro de $P$. maximartinezii, que permita incrementar la tasa de multiplicación de las semillas de este taxon. Dicha aptitud podría reducir el riesgo de extinción al que se enfrenta tal piñonero, dado que la tasa reproductiva es uno de los parámetros más importantes que contribuyen a que una especie se establezca exitosamente en un nicho ecológico. 


\section{CONCLUSIONES}

El protocolo desarrollado es eficiente para la diferenciación de brotes adventicios de Pinus maximartinezii en relación con lo reportado hasta ahora en la literatura.

El uso de cotiledones como explante supera significativamente la respuesta obtenida con embriones. Los brotes adventicios obtenidos pueden, aunque en baja proporción, formar raíces y con ello dar lugar a plantas nuevas.

La propagación in vitro podría formar parte de un programa de conservación de esta especie, debido a la alta tasa de multiplicación que se obtiene con la aplicación del presente protocolo.

\section{LITERATURA CITADA}

Aitken, J., K. J. Horgan y T. A Thorpe. 1981. Influence of explant selection on the shootforming capacity of juvenile tissue of Pinus radiata. Can. J. For. Res. 11: 112-117.

Anónimo. 1999. Procedures guide. Version 8. SAS Institute. Cary, N.C., U.S.A. 1643 pp.

Anónimo. 2002. Norma oficial mexicana NOM-059-ECOL-2001. Instituto Nacional de Ecología-Secretaría de Medio Ambiente y Recursos Naturales. Diario Oficial de la Federación. México, D.F. 88 pp.

Ashihara, H., N. Loukanina, C. Stasolla y T. A. Thorpe. 2001. Pyrimidine metabolism during somatic embryo development in white spruce (Picea glauca). J. Plant Physiol. 158: 613-621.

Barnett, J. P. 1977. Sterilizing southern pine seed with hydrogen peroxide. Tree Planter's Notes 27: 17-19.

Biondi, S. y T. A. Thorpe. 1982. Growth regulator affects metabolite changes in respiration during shoot initiation in cultured cotyledon explants of Pinus radiata. Bot. Gaz. 143: $20-25$.

Calixto, F. y M. S. Pais. 1997. Adventitious shoot formation and plant regeneration from Pinus pinaster Sol. ex Aiton. In Vitro Cell. Dev. Biol. Plant 33: 119-124.

Capuana, M. y R. Giannini. 1995. In vitro plantlet regeneration from embryonic explants of Pinus pinea L. In Vitro Cell. Dev. Biol. Plant 31: 202-206.

Donahue, J. K. y C. Mar-López. 1995. Observations on Pinus maximartinezii Rzed. Madroño 42: $19-25$.

González, M. V., M. Rey, R. Tavazza, S. La Malfa, L. Cuozzo y G. Ancora. 1998. In vitro adventitious shoot formation on cotyledons of Pinus pinea. HortSci. 33: 749-750.

Gresshoff, P. M. y C. H. Doy. 1972. Development and differentiation of haploid Lycopersicon esculentum (tomato). Planta 107: 161-170.

Harry, I. S. y T. A. Thorpe. 1994. Regeneration of plantlets through organogenesis from mature embryos of jack pine. Plant Cell Tiss. Organ. Cult. 37: 159-164. 
Jang, J. C. y F. H. Tainter. 1991. Micropropagation of shortleaf, Virginia and loblolly x shortleaf pine hybrids via organogenesis. Plant Cell Tiss. Org. Cult. 25: 61-67.

Lambardi, M., K. K. Sharma y T. A. Thorpe. 1991. In vitro regeneration of shoot buds and plantlet formation from mature embryos of Pinus halepensis Mill. Acta Hort. 289: 123-124.

Lelu, M. A., C. Bastien, A. Drugeault, M. L. Gouez y K. Klimaszewska. 1999. Somatic embryogenesis and plantlet development in Pinus sylvestris and Pinus pinaster on medium with and without growth regulators. Physiol. Plant. 105: 719-728.

López, M., J. Pacheco, R. Rodríguez y R. Ordás. 1996. Regeneration of plants from isolated cotyledons of salgareño pine (Pinus nigra Arn. ssp. salzmannii (Dunal) Franco. In Vitro Cell. Dev. Biol. Plant 32: 109-114.

López-Mata, L. 2001. Proteins, amino acids and fatty acids composition of nuts from the Mexican endemic rarity, Pinus maximartinezii, and conservation implications. Interciencia 26: 606-610.

Martínez-Pulido, C., I. S. Harry y T. A. Thorpe. 1992. Optimization of bud induction in cotyledonary explants of Pinus canariensis. Plant Cell Tiss. Organ Cult. 29: 247-255.

Martínez-Pulido, C., I. S. Harry y T. A. Thorpe. 1994. Effect of various bud induction treatments on elongation and rooting of adventitious shoots of Canary Island pine (Pinus canariensis). Plant Cell Tiss. Organ Cult. 39: 225-230.

Murashige, T. y F. Skoog. 1962. A revised medium for rapid growth and bioassay with tobacco tissue culture. Physiol. Plant. 15: 473-479.

Nairn, B. J., R. H. Furneaux y T. T. Stevenson. 1995. Identification of an agar constituent responsible for hydric control in micropropagation of radiata pine. Plant Cell Tiss. Organ Cult. 43: 1-11.

Pelletier, G. y S. Laliberté. 2000. Effect of embryo orientation on the developmental sequence of adventitious organogenesis in jack pine (Pinus banksiana Lamb.). Can. J. Bot. 78: 1348-1360.

Reilly, K. y J. Washer. 1977. Vegetative propagation of radiata pine by tissue culture: plantlet formation from embryonic tissue. New Zeal. J. For. Sci. 7: 199-206.

Saborio, F., W. S. Dvorak, J. K. Donahue y T. A. Thorpe. 1997. In vitro regeneration of plantlets from mature embryos of Pinus ayacahuite. Tree Physiol. 17: 787-796.

Schenk, R. U. y A. C. Hildebrandt. 1972. Medium and techniques for induction and growth of monocotyledonous and dicotyledonous plant cell cultures. Can. J. Bot. 50: 199204.

Stojicic, D., S. Budimir y L. Culafic. 1999. Micropropagation of Pinus heldreichii. Plant Cell Tiss. Organ Cult. 59: 147-150.

Sul, I. W. y S. S. Korban. 2004. Effects of salt formulations, carbon sources, cytokinins, and auxin on shoot organogenesis from cotyledons of Pinus pinea L. Plant Growth Regulation 43: 197-205.

Takacs, E. A. 1964. Utilización del agua oxigenada concentrada para estimular la germinación de Pinus taeda L. Suplemento Forestal del Instituto Nacional de Tecnología Agropecuaria. Buenos Aires, Argentina. 46 pp.

Tang, W. y Z. Guo. 2001. In vitro propagation of loblolly pine via direct somatic organogenesis from mature cotyledons and hypocotyls. Plant Growth Regulation 33: 25-31. 
Tang, W., L. C. Harris, V. Outhavong y R. J. Newton. 2004. The effect of different plant growth regulators on adventitious shoot formation from Virginia pine (Pinus virginiana) zygotic embryo explants. Plant Cell Tiss. Organ Cult. 78: 237-240.

Villalobos-Amador, E., G. Rodríguez-Hernández y E. Pérez-Molphe-Balch. 2002. Organogenesis and Agrobacterium rhizogenes-induced rooting in Pinus maximartinezii Rzedowski and P. pinceana Gordon. Plant Cell Rep. 20: 779-785.

Von Arnold, S. y T. Eriksson. 1981. In vitro studies of adventitious shoot formation in Pinus contorta. Can. J. Bot. 59: 870-874.

Webb, K. J. y H. E. Street. 1977. Morphogenesis in vitro of Pinus and Picea. Acta Hort. 78: 259-269.

Recibido en noviembre de 2007.

Aceptado en julio de 2009. 